\title{
17
}

\section{Using Arts-Based Activities to Foster Transformative Learning During a Teaching Practicum in Kenya}

\author{
Glenda Black \& Rogerio Bernardes \\ Nipissing University
}

This essay explores and presents strategies we, as Canadian faculty facilitators of a teaching practicum in Kenya, used to foster the pre-service teachers' knowledge and understanding of critical reflection and transformative learning processes by using arts-based activities. Participation in the arts-based activities while in Kenya encouraged the pre-service teachers to reflect upon and make sense of their cultural, social, and pedagogical experiences, and provided opportunities for them to gain insights that perhaps would not have been revealed using more traditional reflection formats. The transformational learning experienced by the pre-service teachers as they were immersed in artsbased pedagogical activities was evident on a personal and professional level.

\section{Introduction}

$\mathrm{D}$ uring the practicum 22 pre-service teachers and two faculty facilitators from Nipissing University, North Bay, Ontario, were immersed in a Kenyan community. The teaching assignments for the three weeks were in grades 3-7 of a primary school in a rural, agricultural area of the country populated by two different tribal traditions, the Kipsigi and Maasai. We worked directly with the Kenyan classroom teachers in a collaborative teaching enviroment. Outside of school hours our group was invited into the homes, high school, church, and local health facilities of the community. We also contributed to the building of a library and participated in the cultural events of our Kenyan hosts. Following these experiences we applied and expanded the transformational learning process of critical reflection by using arts-based activities to assist the pre-service teachers in addressing some of the disorienting dilemmas they encountered (Merriam, 2004; Mezirow, 1991, 2000). For our preservice teachers these included pedagogical, social, and cultural situations that created cognitive and emotional dissonance.

\section{Transformational Learning Theory}

Transformational learning theory is an adult learning theory based on the fundamental principles that 
adults make meaning and learn from personal experiences (Mezirow, 1991). In transformational learning, life experiences are filtered through one's values, beliefs, and assumptions, mediated and made sense of (Mezirow, 1991). Mezirow (1996) further explains the transformation process as a perspective transformation - a paradigm shift.

Mezirow (2000) developed a multi-phase process of transformational learning. The first step in the process is experiencing a "disorienting dilemma" that prompts one to engage in the second stage of "self examination" due to "feelings of fear, anger, guilt, or shame" (p. 22). In our situation, the dilemmas or issues we had difficulty understanding, one of which is described later in this essay, often led to an initial state of confusion. The step that follows is "critical assessment" of one's assumptions. Kreber (2004) concurs with Mezirow that critical reflection is key to transformational learning. Using Mezirow's categories (content, process, premise) for levels of reflection, Kreber concludes that teacher educators must begin with premise reflection that involves critically "questioning our presuppositions underlying our knowledge" (p. 31). The notion of providing pre-service teachers with the opportunity to reflect critically is supported by Merriam (2004) who stated, "mature cognitive development is foundational to engaging in critical reflection and rational discourse necessary for transformative learning" (p. 65).

During the Kenyan practicum we provided opportunities for the pre-service teachers to experience the traditional forms of reflection such as journaling and peer dialogue. To further foster their learning toward greater critical understanding we also invited the pre-service teachers to question their own assumptions using creative formats.

\section{Arts-Based Activities for Critical Reflection}

While in Kenya, many of the pre-service teachers wore a shirt with the quote, "Be the Change." Of course, this is part of Ghandi's quote, "Be the change you want to see in the world," and refers to the notion that you cannot change the world until you change yourself. It was clear that the pre-service teachers were experiencing personal changes as evidenced in their discussions during our 'highlights of the day, the emotion in their voices as they interacted with community members, and when they taught and played with the children. Nevertheless, recounting the events they experienced was not enough. In support of Merryfield (2000), we, as faculty facilitators, recognized that the Kenyan "experiences alone do not make a person a multicultural or global educator" ( $p$. 440). We acknowledged that for intellectual growth and transformational learning the pre-service teachers needed the opportunity to engage in critical reflection (Merriam, 2004). Criticos (1993) maintained, "effective learning does not follow from a positive experience but from effective reflection” (p. 162).

Although some of the pre-service teachers explored and documented their changes and observations through journaling and photographs, the process of writing reflections in journals did not meet the learning preferences of each group member. The non-journaling pre-service teachers may have been classified as non-reflective if not provided the opportunity to express their thoughts and emotions through alternative forms. We also questioned how much critical reflection was occurring in the journaling. In the traditional forms of recording and discussing reflections, it is possible that the preservice teachers were describing their experiences without critically thinking about them. Building on the transformational learning process of critical reflection we developed and implemented arts-based learning activities that would help our pre-service teachers reflect critically on their experiences and challenge any previously held assumptions. The learning opportunity we assigned met the group's diverse learning needs and fostered inclusivity and transformative learning by helping them confront the disorienting dilemmas they encountered daily.

For our arts-based activity we suggested topics for the pre-service teachers to explore through any medium they chose: visual arts, drama, poetry, song, story, or dance. The activity was presented as an opportunity for the pre-service teachers to think outside the box, collaborate with their colleagues, and have some fun. For convenience, we assigned 
cabin mates for groupings, and the presentations were made to the entire group. The suggested topic list included:

1) Maasai Warriors: Explore how their roles have changed from being warriors to being academics and ambassadors for their culture.

2) Community and Individuality: What we call cheating in the classroom our host teachers call assisting. Explore the tension between these two value systems? Do we privilege one over the other? Is one superior? Can they coexist?

3) Childhood: Explore what it means to be a child in Canada and in Kenya. What should childhood experiences look like? Should every child be guaranteed certain experiences? What are the differences between childhood and adulthood?

4) Identity: Explore your identity as you transition from student to teacher. Has your experience in Kenya changed your idea of who you are as a teacher? As a member of the global community?

5) Power: As White educators visiting a developing country we are privileged in certain ways. Some of these ways are fairly evident, but some are invisible. Explore issues of power and how it is used.

6) The power of Song: As guests in Kenya, we followed the example of our Kenyan hosts and often introduced ourselves by singing songs we had prepared. Explore the power of this practice. How might this be used in Canadian classrooms?

The groups were cautioned not to try and seek answers to any of these questions but rather to start by exploring the pertinent themes whether they be childhood, identity, or community; hopefully by exploring themes and ideas with open minds, the insights would follow. To model our expectations, we presented first. Our topic was the power of stories. Through drama and song, our interactive presentation explored how, in our society, stories and oral traditions have been supplanted by science and 'facts.' We investigated the idea that in North American society facts must be written down and the written word privileged. We contrasted this with the Kipsigi and Maasai tribes who have a rich oral tradition, and how this practice has served them well. The passing down of their history, knowledge, and traditions through oral forms has sustained the continuation of their culture and the survival of their communities for hundreds, and perhaps thousands, of years.

When it was their turn, the pre-service teachers' presentations reflected their diversity as learners. Their topics included those we suggested and some of their own. The following is a summary of a presentation using a drama role play format in which one group explored previously held assumptions regarding cheating. From our preservice teachers' perspective the Kenyan students were cheating during assignments and tests. Classroom conditions forced the Kenyan students to sit shoulder-to-shoulder where they openly looked off each other's work and often exchanged papers. After trying a variety of failed strategies to prevent cheating, our pre-service teachers were clearly exasperated, in part because they knew that their Kenyan pupils would face national standardized examinations. It was decided that they would ask the Kenyan host teachers for help. The reply was that the students were not cheating but rather assisting each other. Initially, our pre-service teachers were perplexed by this reply because the Kenyan students' actions would clearly be labeled as cheating in any North American school. Through their role play presentation and subsequent discussion our group began to understand how Kenyan culture was deeply invested in the value of community. They role played the consequences of a hunter who would not share his catch in times of hunger, and the owner of a homestead who would not share his well water in times of drought. How would the community 
survive? Along the same line of thought, if everyone in a community is willing to share, does it matter who has the knowledge? In contrast, they noted examples and became deeply aware of how North American society and our educational systems are deeply invested in the values of independence, individuality, and competition.

It was precisely because we were immersed in a different culture and experienced the immediate effects of community (students assisting in this instance) that we were confronted with our own assumptions. However, it was the arts-based activities that provided the necessary vehicles for our students to directly confront their disorienting dilemmas and fully appreciate the position of the Kenyan students and teachers. In the words of one pre-service teacher:

"There are things that I learned that could not really be taught or have the same effect unless you have experienced it first hand. Some of the things that changed me the most and impacted me were experiences that we had, but most importantly the feelings and emotions that came with those experiences. It's not something that someone else could understand without going through this themselves."

Another pre-service teacher commented:

"My experience in Kenya has opened my eyes to a variety of new experiences. Going back into a Canadian classroom, I will definitely embrace cultural difference in a different way. I feel that I will use the diversity of a classroom as a teaching tool. I will take time for storytelling and make it fit into the curriculum. I have also learned the importance of community and feel a strong urge to make my classroom a big community, more so than I did before I left."

\section{Relevance for Teacher Educators}

As teacher educators we emphasize the importance of reflection to improve our professional practice. As practicum faculty facilitators, we learned that we needed to provide the strategies to encourage critical reflection and transformative learning. Critical thinking and transformative learning does not happen by itself. In our classrooms we instruct our pre-service teachers to differentiate instruction for their students. We must model the concept of differentiation and provide instructional strategies to meet the diverse needs of our learners. The arts-based activities met the diverse learning needs of the group and allowed the pre-service teachers to examine their own biases, personally experience other ways of knowing, and actively engage in transformative cross-cultural experiential learning.

\section{References}

Criticos, C. (1993). Experiential learning and social transformation for a post-apartheid learning future. In D. Boud, R. Cohen, \& D. Walker (Eds.), Using experience for learning (pp. 159165). Maidenhead, Berkshire, UK: Open University Press

Kreber, C. (2004). An analysis of two models of reflection and their implications for educational development. International Journal for Academic Development 9(1), 2949.

Merriam, S.B. (2004). The role of cognitive development in Mezirow's transformational learning theory. Adult Education Quarterly, 55(1), 60-68.

Merryfield, M.M. (2000). Why aren't teachers being prepared to teach for diversity, equity, and global interconnectedness? A study of lived experiences in the making of multicultural and global educators. Teaching and Teacher Education, 16(4), 429-443. 
Mezirow, J. (2000). Learning to think like an adult: Core concepts of transformation theory. In J, Mezirow \& Associates (Eds.), Learning as transformation (pp. 3-34). San Francisco: Jossey-Bass

Mezirow, J. (1996). Contemporary paradigms of learning. Adult Education Quarterly, 46(3), 158-172.

Mezirow, J. (1991). Transformative dimensions in adult learning. San Francisco, CA: JosseyBass.

\section{Biographies}

Glenda Black is an Assistant Professor in the Schulich School of Education, Nipissing University, North Bay, Ontario. She teaches curriculum related courses in the B.Ed. program, and educational leadership courses in the Graduate Studies program. Her research interests include: educational leadership, curriculum development and instruction, and indigenous and cross-cultural education.

Rogerio Bernardes is an Assistant Professor in the Schulich School of Education, Nipissing University, North Bay, Ontario. He teaches Physical and Health Education. His research interests include teaching approaches that are inclusive of bigger bodies in physical education and international and crosscultural education.. 